\title{
DISKURSNI MARKERI U AKADEMSKIM PREDAVANJIMA IZ ELEKTROTEHNIKE I MAŠINSKE TEHNIKE
}

\begin{abstract}
Sažetak
Diskursni markeri pripadaju grupi jezičkih elemenata čija se funkcija posmatra prevashodno kao konektivna, odnosno, povezivačka. Pored toga, diskursni markeri posmatraju se kao suštastveno komunikativni elementi značenja.

$\mathrm{Na}$ osnovu analizirane literature, utvrdili smo kriterijume na osnovu kojih su diskursni markeri analizirani na primerima dobijenim iz korpusa u vidu akademskih predavanja iz elektrotehnike i mašinske tehnike. $U$ radu, nastojimo da dosledno primenimo kriterijume i da utvrdimo obrasce ponašanja analiziranih jezičkih jedinica barem kada su u pitanju diskurs elektrotehnike i mašinske tehnike.

U prvom delu dajemo uvodna razmatranja o leksičkim jedinicama koje su predmet ovog istraživanja. U narednom delu, posmatramo diskursne markere u relevantnoj lingvističkoj literaturi. Zatim, sledi detaljan opis korišćenog korpusa. U narednom delu, navodimo neke karakteristike diskursnih markera, kao i relevantne kriterijume koje smo našli u literaturi. Zatim, sledi analiza diskursnih markera u korpusu. $U$ ovom delu, ispitujemo primenjljivost opisanih kriterijuma na konkretnom jezičkom materijalu. U poslednjem delu iznosimo zaključne napomene o ispitivanim jezičkim fenomenima.
\end{abstract}

Ključne reči: diskursni markeri, akademska predavanja, sintaksa, semantika, analiza diskursa, podaci zasnovani na korpusu, diskurs elektrotehnike, diskurs mašinske tehnike.

\subsection{Uvodna razmatranja}

Leksičke jedinice, poput but, so, in fact, kind of i sort of, proučavane su u lingvističkoj literaturi pod različitim nazivima. Prema literaturi, Levinson je prvi ukazao na to da bi diskursni markeri mogli da zavređuju da se proučavaju (Fraser 1988: 19; Fraser 1990: 384; Levinson 1983: 87-88). U međuvremenu, diskursni markeri su postali predmet različitih izučavanja u proteklih trideset godina (Fraser 2009: 293). 
U ovom radu, fokusiram se na ovu malu grupu jezičkih jedinica koje predstavljaju granične slučajeve semantičko-pragmatičkog interfejsa. Izvesni autori konstatuju da se ovakve jezičke jedinice nalaze između semantike i pragmatike (Dascal and Katriel 1977: 143-172). Pošto se izučavanje ovih jezičkih pojava pretvorilo u razvijenu industriju (Fraser 1999), onda nije iznenađujuće što izvesni autori koriste donekle različite termine kako bi definisali slične jedinice koje razmatraju. Neki autori ove jezičke jedinice nazivaju natuknice (cue phrases) (Litman and Hirschberg 1990), diskursni konektivi (discourse connectives (Rouchota 1996), semantički konjunkti (semantic conjuncts) (Quirk et al. 1985), rečenični konektivi (sentence connectives) (Halliday and Hasan 1976), da nabrojim samo neke od naziva i autora. U ovom radu, usvojiću, bez ikakvih preskriptivnih namera, termin diskursni marker (discourse marker), koji prema nekim autorima predstavlja prikladan opšti termin, jer je, čini se, u najširem opticaju i sa najmanjim ograničenjima u primeni, a istovremeno, ovaj termin nam omogućava da podvedem raznolike elemente pod jedan konceptualni kišobran (Jucker and Ziv 1998: 2).

$\mathrm{S}$ obzirom da diskursni markeri nisu u značajnoj meri proučavani u specifičnim diskursima, onda su se našli u fokusu mog istraživanja ${ }^{1}$.

\subsection{Diskursni markeri u lingvističkoj literaturi}

Diskursne markere obrađuje Predrag Piper u okviru svoje studije, posebno se osvrćući na njihovu ulogu u temporalnoj lokalizaciji (Piper 1997). Ovaj lingvista ističe „iako termin diskursni marker nije nov, njegova upotreba nije raširena." (Piper 1997: 174). Pošto je Piper, prema mom najboljem saznanju, prvi rasvetlio terminološku konfuziju i prvi preveo termin diskursni marker na ovim našim prostorima, i to u svojoj studiji iz 1997. godine, onda sam i upravo usvojio njegov prevodni ekvivalent diskursni marker. Sem toga, Predrag Piper daje jednu prilično solidno definiciono određenje, naglasivši da se pod diskursnim markerima:

„[...] shvataju oni delovi teksta, obično intonacijski ili interpunkcijski izdvojeni, kojima se ističe njihova tematska konfiguracija, ostvarena početkom i

1 Pa ipak, postoje autori koji se bave spefičnim diskursnim markerima u izvesnim diskursima (vidi npr. Đurić 2012: 49-64). 
završetkom teksta, i počtkom/završetkom svakog njegovog smisaono relativno samostalnog fragmenta (nadrečenične celine), kao nosioca informacije koja se želi izdvojiti kao komunikativno manje ili više zasebna." (Piper 1997: 174).

lako neki autori primećuju da se većina istraživača slaže u tome da diskursni markeri povezuju diskursne segmente, ipak se u literaturi konstatuje da ne postoji saglasnost kako treba definisati diskursne markere niti kako oni funkcionišu (Fraser 1999: 931). Ipak, čini se da su autori saglasni u tome da diskursni markeri igraju raznovrsne važne uloge u interpretaciji iskaza (Schourup 1999: 227).

Frejzer definiše diskursne markere kao jedinice koje pripadaju pragmatičkoj klasi, ili preciznije, kao leksičke jedinice dobijene iz sintaksičke klase veznika, adverbijala i predloških fraza (Fraser 1999: 950). Uz izvesne izuzetke, diskursni markeri signaliziraju odnos između interpretacije diskursnog segmenta koji uvode, koji Frejzer naziva S2, i prethodnog segmenta, koji Frejzer naziva S1. Pored toga, diskursni markeri imaju have a core meaning, koje je proceduralno. Na dalje, specifičniju interpretaciju ovih diskursnih jedinica određuje kontekst.

Neki autori analiziraju diskursne markere u pogledu toga da li ove jezičke jedinice ispoljavaju konceptualna ili proceduralna svojstva, a nekada dovode i u pitanje takve dihotomije (Shloush 1998: 61-82). Citirana autorka obezbeđuje objedinjeno tumačenje hebrejskog diskursnog markera bekicur.

Prilikom proučavanja usmenog diskursa, koji je predmet i ove studije, pojedini autori koriste i kvantitativne podatke prilikom analize specifičnih diskursnih markera koji imaju leksički izvor koji obuhvata poređenje (Maschler 2001: 295-326). Takođe, u konsultovanoj literaturi, diskursni markeri se posmatraju u pogledu interpersonalnih, referencijalnih, strukturalnih i kognitivnih kategorija, a određuju se kao odelita i jedinstvena kategorija jezičkih jedinica (Maschler 1997: 183-211).

Prema izvesnim autorima, termin diskursni marker tipično se odnosi na manje ili više otvorenu klasu sintaksički neobaveznih, povezivačkih izraza koji nisu istinosno uslovljeni (Schourup 1999: 242). Prilično široko određenje nalazimo i autoritativnim lingvističkim rečnicima, poput Oksfordskog, gde autori definišu diskursne markere kao raznovrsne jedinice koje zadobijaju funkciju u okviru većeg diskursa pre nego u okviru zasebne rečenice ili klauze (Matthews 2005: 101). Kao svoju polaznu tačku, uzeću upravo delimitaciju koju predlazu tri citirana autora (Fraser, Schourup i Matthews) kako bih tretirao diskursne markere u akademskom diskursu elektrotehnike. 


\subsection{Opis korpusa}

lako se govorni diskurs ${ }^{2} \mathrm{u}$ velikoj meri korist $\mathrm{u}$ istraživanjima diskursnih markera, želeo sam da proširim opseg tako što bih obradio i analizirao usmeni medijum u obliku deset akademskih predavanja održanih na fakultetima za elektrotehniku i mašinsku tehniku na Masačusetskom institutu za tehnologiju (MIT). Preciznije, usmeni medijum se sastoji od pet akademskih predavanja iz oblasti elektrotehnike (a ovih pet korpusa, dalje u tekstu ćemo označavati kao sledeće inicijalizme: EEC1, EEC2, EEC3, EEC4, EEC5) i pet akademskih predavanja iz oblasti mašinske tehnike (za koje koristimo sledeće inicijalizme: MEC1, MEC2, MEC3, MEC4, MEC5). Ova predavanja su transkribovana i anotirana u skladu sa postojećom literaturom (Jenks 2011; Polovina 1987; Savić i Polovina 1989; Tannen 1989; Schiffrin 2006). Grafičku prezentaciju korpusa i notacioni sistem za moje ekscerpte adaptirao sam na osnovu relevantne literature (vidi: Polovina 1987; Schiffrin 2006; Tannen 1989).

Korpusi EEC1-5 i MEC1-5 statistički su analizirani pomoću standardnog Microsoft Excel 2007 programa, a prethodno su pripremljeni u formatu standardnog Microsoft Word 2007 dokumenta. Nakon procesa konvertovanja statistički korpus EEC1 obuhvata 12 strana i sadrži 9488 reči u 588 redova, EEC2 sadrži 11 strana i 9226 reči u 541 redu, EEC3 dug je 11 strana, sadrži 8820 reči u 529 redova, EEC4 obuhvata 10 strana, sadrži 8238 reči raspoređenih u 489 redova, a EEC5 sadrži 12 strana koje sadrže 9450 reči raspoređenih u 571 redu. Korpus MEC1 sadrži 33 strane, 16797 reči u 1629 redova, MEC2 sadrži 30 strana, 16621 reči u 1473 reda, MEC3 dug je 33 strane koje sadrže 16724 reči raspoređenih u 1644 reda, MEC4 sadrži 30 strana, 15445 reči u 1469 redova, a MEC5 je dug 34 strane, sadrži 18034 reči raspoređenih u 1683 reda. Drugim rečima, korpusi EEC1-5 i MEC1-5 obuhvataju 216 strana, sadrže 128843 reči i 10616 redova.

Pre nego što analiziramo primere iz našeg korpusa, u sledećem odeljku, pogledaćemo neke karakteristike diskursnih markera, prema konsultovanoj literaturi, kao i definicione kriterijume za određenje diskursnih markera. relevantnoj literaturi stručnjaka za analizu diskursa Igora Lakića (vidi: Lakić 1999). 


\subsection{Neke karakteristike diskursnih markera i relevantni kriterijumi}

lako definiciono određenje diskursnih markera i kriterijumi za njihovu klasifikaciju zavise od teorijskog modela koji uzimamo za njihovo proučavanje, smatramo da se mogu izvući neke njihove zajedničke karakteristike. Na osnovu pregledane i citirane relevantne literature koja se bavi diskursnim markerima, informisao sam se o fonološkim, leksičkim, sintaksičkim, semantičkim i funkcionalnim karakteristikama diskursnih markera ${ }^{3}$. Diskursni markeri su kratki, fonološki redukovani oblici koji obrazuju odelitu tonsku grupu, a često se ne mogu uklopiti u definicioni status tradicionalne vrste reči. U vezi sa sintaksičkim osobenostima, može se reći, na osnovu literature, da su diskursni markeri sintaksički izdvojeni elementi koji zauzimaju inicijalni položaj u iskazu ili rečenici. Takođe, ove jedinice su sintaksički neobavezne. Semantički posmatrano, diskursni markeri nemaju nikakvo propozicionalno značenje, ili je pak prisutno neznatno propozicionalno značenje. U pogledu funkcionalih obeležja, može se konstatovati da su diskursni markeri zapravo multifunkcionalni izrazi koji istovremeno deluju na različitim jezičkim nivoima.

U pregledanoj i konsultovanoj relevantnoj lingvističkoj literaturi koja se bavi diskursnim markerima, ustanovljeni su kriterijumi koji se, uslovno rečeno, mogu podeliti na definicione i neobavezne kriterijume (Schourup 1999). Citirani autor navodi sedam ovakvih kriterijuma, koje ćemo u odeljku u kome analiziramo primere iz korpusa, primeniti na naše ekscerpte $\mathrm{i}$ ispitati ih na konkretnom jezičkom materijalu elektrotehnike i mašinske tehnike. Prema prvom kriterijumu konektivnosti, diskursni markeri povezuju segmente u diskursu (Schourup 1999: 230). Prema drugom kriterijumu opcionalnosti, diskursni markeri nisu obavezni elementi (Schourup 1999: 231). Prema trećem kriterijumu, diskursni markeri

Pored navedenih karakteristika u literaturi, izvesni autori govore i o sociolingvističkim karakteristikama. Na primer, ističu da su diskursni markeri učestali u govoru (međutim, nigde ne navode statistički relevantne podatke za takve svoje zaključke, kako bismo utvrdili da li su validni), ili pak (krajnje neopravdano) ističu da su diskursni markeri učestali u govoru žena i neformalnom stilu, ali se opet ne pozivaju, niti navode relevantne statističke podatke za ovakve proizvoljne tvrdnje. Štaviše, istraživanja koja sprovodim na statistički relevantnom uzorku (vidi: odeljak 1.2. koji sadrži detaljan opis mog korpusa korišćenog u ovom radu) idu u prilog suprotnim tvrdnjama. U mom korpusu, isključivo su snimani elektroinženjeri mašinski inženjeri muškog pola koji statistički frekventno koriste diskursne markere. Pored toga, diskursni markeri se koriste u akademskim predavanjima, dakle, na vrlo formalnom nivou i to u renomiranim institucijama, poput Masačusetskog instituta za tehnologiju. 
ne utiču na istinosne uslove, a prema četvrtom, diskursni markeri nisu sintaksički integrisani (Schourup 1999: 232). Peti kriterijum nalaže da diskursni markeri prototipično zauzimaju inicijalni položaj u iskazu/rečenici (Schourup 1999: 233). Šesti kriterijum nalaže da se diskursni markeri vezuju za govorni medijum (Schourup 1999: 234). Sedmi kriterijum multikategrijalnosti nalaže da diskursni markeri imaju različito poreklo (Schourup 1999: 234), a ova multikategorijalnost diskursnih markera objašnjava se dijahronijski na osnovu procesa gramatikalizacije. Ovim su iscrpljeni kriterijumi koji se pretežno koriste u literaturi.

U sledećem delu rada sledi analiza izabranih diskursnih markera na materijalu akademskih predavanja.

\subsection{Analiza diskursnih markera u korpusu}

U ovom delu rada, analiziramo diskursne markere but, so, in fact, kind of $\mathrm{i}$ sort of $\mathrm{u}$ akademskim predavanjima iz obasti elektrotehnike i mašinske tehnike. Prema literaturi (Fraser 1999: 938), diskursni markeri dele jednu zajedničku osobinu. Naime, oni nameću odnos između nekog aspekta diskursnog segmenta koji sačinjavaju (koji se prema Fraseru identifikuje kao S2) i neki aspekt prethodnog diskursnog segmenta (koji ovaj autor označava oznakom S1). Drugim rečima, S2 i S1 funkcionišu kao relacija dve diskursne lokacije. Ili preciznije, jedan argument se nalazi u segmentu koji uvode diskursni markeri, a drugi segment se nalazi u prethodnom diskursu. Citirani autor ovaj kanonički oblik predstavlja na sledeći način: <S1. DM+S2>.

Imajući u vidu navode iz literaure, ilustrovaću njegove opservacije uz pomoć ekscerpata iz mog korpusa. Drugim rečima, pogledaću ovaj kanonički oblik na materijalu akademskih predavanja elektrotehnike i mašinske tehnike 4 .

(1) [EEC2: 23-23] So, big O corresponds roughly to less than or equal to. But this is the formalization.

(2) [MEC4: 136-139] Usually the way we operate, at least in our area, the aerodynamic area, we had a crack team that would go back in and define the problem, a potential solution to that problem and then suggest to the contractor they might look at this way or that way. But they really put the muscle to it.

U ekscerptima (1) i (2), diskursni marker but ponaša se u skladu sa

$4 \quad$ U mojim ekscerptima, diskursni markeri su podvučeni i obeleženi kurzivom, istovremeno. 
navedenim kanoničkim oblikom ${ }^{5}$. Drugim rečima, ekscerpti (1) i (2) imaju kanonički oblik koji se obeležava na sledeći način: <S1. But+S2>. Međutim, u literaturi se dozvoljavaju i izvesne varijacije, od kojih je najčešća sledeća: <S1, DM+S2>. Pogledaćemo da li se ova varijacija javlja u mom korpusu.

(3) [EEC1: 163-164] There are other resources that we may care about, $\underline{\text { but }}$ predominantly we focus on performance.

(4) [MEC1: 38-40] The best job I ever had, you might say, really, is I've had a lot of different jobs, $\underline{\text { but }}$ my first job was really working with the MIT Instrumentation Laboratory where I met a great number of people.

Ekscerpti (3) i (4) ispoljavaju i demonstrraju navedenu varijaciju $(<\mathrm{S} 1$, but+S2>).

Pogledaćemo sintaksu i semantiku diskursnih markera u akademskom diskursu, na osnovu opisanih karakteristika u literaturi. Prema nekim autorima, sintaksički posmatrano, diskursni markeri izgleda ne čine odelitu sintaksičku kategoriju (Fraser 1999: 943). Što se tiče semantike, autori konstatuju da jedinice koje funkcionišu kao diskursni markeri povezuju dva diskursna segmenta i ne doprinose propozicionom značenju tih dvaju segmenata (Fraser 1999: 944).

$\mathrm{U}$ delu koji sledi, analiziram diskursne markere u vezi sa sedam pomenutih kriterijuma (vidi odeljak 1.2. u ovom radu). Pokušaću da primenim ove kriterijume na pimere iz mog korpusa. No, pre nego što počnem analizu, samo ću ih ukratko rezimirati. Dakle, prema ovim kriterijumima, diskursni markeri povezuju segmente u diskursu, nisu obavezni elementi i ne utiču na istinosne uslove. Sem toga, diskursni markeri nisu sintaksički integrisani, a zauzimaju (uglavnom) inicijalni položaj, vezuju se za govorni medijum i imaju različito poreklo.

Pogledaćem ove kriterijume na primeru markera but, so, in fact, kind of i sort of, koje ilustrujemo sledećim ekscerptima:

(5) [EEC4: 51-52] But if it is less than or equal to $x$, I have got a problem if I want to maintain the invariant if this next element is less than or equal to $x$.

(6) [EEC4: 23-24] You just recursively sort the two subarrays. So, I recursively sort the elements less than or equal to $x, I$ recursively sort the elements greater than or equal to $x$.

(7) [EEC4: 267-269] I simply plugged in, for $U(n / 2)$, this recurrence. In fact, technically I guess I should have said Theta(n/2) just to make this substitution more straightforward.

$5 \quad$ Zanimljivo je da u ekscerptu (1) drugom iskazu koji započinje diskursnim markerom but, prethodi iskaz u kome se u inicijalnom položaju nalazi diskursni marker so. 
(8) [EEC4: 129-131] That is actually kind of important to understand, because it turns out the most common thing to sort is something that is already sorted, surprisingly, or things that are nearly sorted.

(9) [EEC4: 29-30] Just as mergesort was recursive merging, quicksort sort of goes the other way around and does recursive partitioning.

(10) [MEC2: 281-283] But, independent of that, you never fly in space something that is close to the state-of-the-art because you have to go through all the qualifications, which takes a lot of time, and it has to be radiation hardened when you're in space.

(11) [MEC2: 337-338] If you get unbalanced flow of hypergolic propulsion systems you can also get an explosion. So, the solution to that was limiting how many jets you could fire at one time off of one tank.

(12) [MEC2: 1395-1396] Miwa Hayashi is, in fact, at NASA Ames Research Center now, was here at MIT and worked on the design of the next generation of the Shuttle cockpit upgrade.

(13) [MEC2: 808-810] The original expected launch date of the Shuttle was '78. It kind of stayed ahead of us a certain amount of time, but we had probably $90 \%$ or $95 \%$ of the design done by ' 78 .

(14) [MEC2: 1400-1402] I might add that, although the room is very crowded, if a few of you would like to sort of hear where this story would have gone, you're welcome to come across the hall to 419 and hear Dr. Hayashi.

Ekscerpti (5-14) ispoljavaju izvesne obrasce ponašanja koje se javlja u korpusu diskursa elektrotehnike i mašinske tehnike, pa ćemo ih pogledati.

Diskursni markeri but, so, in fact, kind of i sort of ispunjavaju kriterijum opcionalnosti kako u diskursu elektrotehnike (ekscerpti (5-9)), tako i u diskursu mašinske tehnike (ekscerpti: (10-14)). Drugim rečima, uklanjanje pomenutih diskursnih markera ne bi izmenilo gramatičnost iskaza u kome se javljaju. Sledstveno tome, izostavljanje but, so, in fact, kind of i sort of ne čini dobijeni diskurs negramatičnim niti nerazumljivim. Međutim, ipak bi konstatovali da ovi markeri nisu beskorisni niti redundantni. Istovremeno ispitivani markeri u ekscerptima (5-14) povezuju segmente u diskursu.

$\mathrm{Na}$ dalje, primetili smo da svi posmatrani diskursni markeri u ekscerptima (5-14) ne utiču na istinosne uslove. Takođe, u ekscerptima (5-14), diskursni markeri nisu sintaksički integrisani.

$\mathrm{U}$ pogledu petog kriterijuma, primećeno je da markeri but, so i in fact zadovoljavaju ovaj kriterijum, odnosno, zauzimaju inicijalni položaj. Međutim, to nije slučaj sa markerima kind of i sort of, koji zauzimaju medijalni položaj u ekscerptima (8), (9), (13) i (14). Svi markeri ispunjavaju šesti krtierijum pošto 
se svi javljaju u gvornom medijumu, odnosno, preciznije u akademskim predavanjima iz oblasti elektrotehnike i mašinske tehnike. Takođe, svi markeri zadovoljavaju poslednji kriterijum zato što se multikategorijalnost može obasniti u dijahronijskom smislu na osnovu procesa gramatikalizacije.

Na osnovu ovih kriterijuma, može se reći da su ispitivani diskursni markeri u diskursu elektrotehnike i mašinstva sintaksički neobavezni izrazi koji ne utiču na istinosne uslove diskursnih segmenata koje uvode, a istovremeno povezuju segment $u$ kome se javljaju sa segmentom koji im neposredno prethodi.

$U$ narednom delu, iznose se zaključne napomene $u$ vezi sa ispitivanim jezičkim jedinicama.

\subsection{Diskusija i zaključne napomene}

Nakon pregleda relevantne literature, utvrdili smo da ne postoji jedinstvena i univerzalna definicija diskursnih markera. Videli smo da ovakvo stanje stvari utiče i na to da se ovi fenomeni na različite načine definiciono određuju i klasifikuju. Na osnovu analize primera iz korpusa, pokazalo se da iako diskursni markeri možda ne čine jedinstvenu gramatičku klasu, postoje izvesne karakteristike koje ih mogu svrstati u jedan skup jezičkih pojava, barem prema izvesnim kriterijumima. Takođe, na osnovu pregleda literature, ali i analizom primera iz korpusa, primetili smo da diskursni markeri jesu sintaksički izdvojeni elementi koji (uglavnom) zauzimaju inicijalni položaj u iskazu, a predstavljaju jezičke jedinice bez ikakvog ili neznatnog propozicionalnog značenja. Istovremeno, pokazalo se da su ove leksičke jedinice multifunkcionalne i da istovremeno deluju na različitim jezičkim nivoima.

Utvrdili smo da ispitivani diskursni markeri uglavnom ispunjavaju u velikoj meri sedam kriterijuma predloženih u literaturi. Preciznije, u ispitanim ekscerptima, diskursni markeri povezuju segmente u diskursu, nisu obavezni elementi, ne utiču na istinosne uslove, nisu sintaksički integrisani, zauzimaju inicijalni položaj (mada smo videli da dva markera zauzimaju medijalni položaj), vezani su za govorni medijum i imaju različito poreklo. Na osnovu ispitivanja primenjivosti kriterijuma, možemo izvesti jedan tentativan zaključak kojim bi definiciono odredili diskursne markere (ali samo na materijalu koji smo mi ispitivali, odnosno, u akademskim predavanjima iz oblasti elektrotehnike i mašinstva) kao sintaksički neobavezne jezičke jedinice i elemente diskursa koji ne utiču na istinosne uslove diskursnog segmenta koji uvode, povezujući dati diskursni segment u 
kome se javljaju sa diskursnim segmentom koji im neposredno prethodi. Ovi nalazi predstavljaju samo neke naznake u pokušaju da se analiziraju i objasne diskursni markeri u diskursu elektrotehnike i mašinstva, koji bi mogli da posluže kao polazna tačka za dalja istraživanja.

\section{Literatura}

Dascal, Marcelo and Tamar Katriel. "Between Semantics and Pragmatics: The Two Types of 'But' - Hebrew 'Aval' and 'Ela'." Theoretical Linguistics 4 (1977): 143-172. Print.

Đurić, Miloš D. "The Relevance of Discourse Connectives: The Case of English but and French mais in the Discourse of Electrical Engineering." Voicing the Alternative: Essays in Language and Literary Studies, ed. Aleksandra Nikčević-Batrićević and Marija Krivokapić, 49-64. Nikšić: Faculty of Philosophy, University of Montenegro, 2012. Print.

Fraser, Bruce. "Types of English Discourse Markers." Acta Linguistica Hungarica 38 (1-4) (1988): 19-33. Print.

Fraser, Bruce. "An Approach to Discourse Markers." Journal of Pragmatics 14 (1990): 383-395. Print.

Fraser, Bruce. "What are discourse markers?." Journal of Pragmatics 31 (1999): 931-952. Print.

Fraser, Bruce. "An Account of Discourse Markers." International Journal of Pragmatics 1 (2009): 293-320. Print.

Halliday, Michael Alexander Kirkwood, and Ruqaiya Hasan. Cohesion in English. London: Longman, 1976. Print.

Jenks, Christopher Joseph. Transcribing Talk and Interaction. Amsterdam: John Benjamins, 2011. Print.

Jucker, Andreas H., and Yael Ziv. "Discourse markers: Introduction." Discourse markers: Descriptions and Theory, ed. Andreas H. Jucker and Yael Ziv, 1-12. Amsterdam: John Benjamins, 1998. Print.

Lakić, Igor. Analiza žanra: Diskurs jezika struke. Podgorica: Institut za strane jezike u Podgorici i Univerzitet Crne Gore, 1999. Print.

Levinson, Stephen C. Pragmatics. Cambridge: Cambridge University Press, 1983. Print.

Litman, Diane, and Julia Hirschberg. "Disambiguating cue phrases in text and speech." Papers Presented to the 13th International Conference on Computational Linguistics, 1990, 251-256. Print.

Maschler, Yael. "Discourse Markers at Frame Shifts in Israeli Hebrew Talk-in-Interaction." Pragmatics 7 (2), (1997): 183-211. Print.

Maschler, Yael. "veke'ilu haragláyim sh'xa nitka'ot bifním kaze ('and like your feet get stuck inside like'): Hebrew kaze ('like'), ke'ilu ('like'), and the Decline of Israeli dugri ('direct') Speech." Discourse Studies 3 (3), (2001): 295-326. Print.

Matthews, P. H. Oxford Concise Dictionary of Linguistics. Oxford: Oxford University Press, 2005. Piper, Predrag. Jezik i prostor. Beograd: Biblioteka XX vek i Čigoja štampa, 1997.

Polovina, Vesna. Leksičko-semantička kohezija u razgovornom jeziku. Beograd: Filološki fakultet, Univerzitet u Beogradu, 1987. Print. 
Quirk, Randolph, Sidney Greenbaum, Geoffrey Leech and Jan Svartvik. A Comprehensive Grammar of the English Language. London: Longman, 1985. Print.

Rouchota, Villy. "Discourse Markers: What Do They Link?." UCL Working Papers in Linguistics 8, eds. John Harris and Philip Backeley, (1996): 199-214. London: University College London, 1996. Print.

Savić, Svenka, i Vesna Polovina. Razgovorni srpskohrvatski jezik. Novi Sad: Institut za južnoslovenske jezike Filozofskog fakulteta, 1989. Print.

Schiffrin, Deborah. In Other Words: Variation and Reference in Narrative. Cambridge: Cambridge University Press, 2006. Print.

Schourup, Lawrence. "Discourse markers - Tutorial Overview" Lingua 107, 3-4, (1999): 227-265. Print.

Shloush, Shelley. "A Unified Account of Hebrew bekicur 'in short': Relevance Theory and Discourse Structure Considerations." Discourse Markers: Descriptions and Theory, eds. Andreas H. Jucker and Yael Ziv, 61-82, Amsterdam: John Benjamins, 1998. Print.

Tannen, Deborah. Talking Voices: Repetition, Dialogue and Imagery in Conversational Discourse. Cambridge: Cambridge University Press, 1989. Print.

Miloš D. Đurić

Faculty of Electrical Engineering

University of Belgrade

\title{
DISCOURSE MARKERS IN ACADEMIC LECTURES ON ELECTRICAL ENGINEERING AND MECHANICAL ENGINEERING
}

\begin{abstract}
Summary
The aim of this paper is to describe and explain discourse markers in the discourses of electrical engineering and mechanical engineering. One part of the paper surveys research on discourse markers, whilst another introduces the scope and corpus-based data. Additionally, I list the most relevant findings about the investigated discourse markers and discuss the applicability of the criteria found in the pertinent linguistic literature.

Key Words: Discourse Markers, Academic Lectures, Syntax, Semantics, Discourse Analysis, Corpus-Based Data, Electrical Engineering Discourse, Mechanical Engineering Discourse.
\end{abstract}

